\title{
Neuropilin-1 promotes the oncogenic Tenascin-C/integrin $\beta 3$ pathway and modulates chemoresistance in breast cancer cells
}

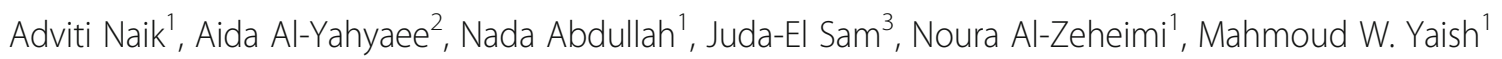
and Sirin A. Adham ${ }^{1 *}$ (D)

\begin{abstract}
Background: Neuropilin-1 (NRP-1), a non-tyrosine kinase glycoprotein receptor, is associated with poor prognosis breast cancer, however transcriptomic changes triggered by NRP-1 overexpression and its association with chemoresistance in breast cancer have not yet been explored.

Methods: BT-474 NRP-1 variant cells were generated by stable overexpression of NRP-1 in the BT-474 breast cancer cell line. RNA sequencing and qRT-PCR were conducted to identify differentially expressed genes. The role of an upregulated oncogene, Tenascin C (TNC) and its associated pathway was investigated by siRNA-mediated knockdown. Resistant variants of the control and BT-474 NRP-1 cells were generated by sequential treatment with four cycles of Adriamycin/Cyclophosphamide (4xAC) followed by four cycles of Paclitaxel (4xAC + 4xPAC).

Results: NRP-1 overexpression increased cellular tumorigenic behavior. RNA sequencing identified upregulation of an oncogene, Tenascin-C (TNC) and downregulation of several tumor suppressors in BT-474 NRP-1 cells. Additionally, protein analysis indicated activation of the TNC-associated integrin $\beta 3$ (ITGB3) pathway via focal adhesion kinase (FAK), Akt (Ser473) and nuclear factor kappa B (NF-kB) p65. siRNA-mediated TNC knockdown ablated the migratory capacity of BT-474 NRP-1 cells and inactivated FAK/Akt473 signaling. NRP-1 overexpressing cells downregulated breast cancer resistance protein (BCRP/ABCG2). Consequently, sequential treatment with Adriamycin/ Cyclophosphamide (AC) cytotoxic drugs to generate resistant cells indicated that BT-474 NRP-1 cells increased sensitivity to treatment by inactivating NRP-1/ITGB3/FAK/Akt/NF-kB p65 signaling compared to wild-type BT-474 resistant cells.

Conclusions: We thus report a novel mechanism correlating high baseline NRP-1 with upregulated TNC/TGB3 signaling, but decreased ABCG2 expression, which sensitizes BT-474 NRP-1 cells to Adriamycin/Cyclophosphamide. The study emphasizes on the targetability of the NRP-1/ITGB3 axis and its potential as a predictive biomarker for chemotherapy response.
\end{abstract}

Keywords: Breast cancer, NRP-1, ABCG2, TNC, Integrin beta 3, Chemoresistance, Adriamycin, Cyclophosphamide

\footnotetext{
* Correspondence: sadham@squ.edu.om; sirinadham@yahoo.com

${ }^{1}$ Department of Biology, College of Science, Sultan Qaboos University, P. O.

Box 36, Muscat, Oman

Full list of author information is available at the end of the article
}

(c) The Author(s). 2018 Open Access This article is distributed under the terms of the Creative Commons Attribution 4.0 International License (http://creativecommons.org/licenses/by/4.0/), which permits unrestricted use, distribution, and reproduction in any medium, provided you give appropriate credit to the original author(s) and the source, provide a link to the Creative Commons license, and indicate if changes were made. The Creative Commons Public Domain Dedication waiver (http://creativecommons.org/publicdomain/zero/1.0/) applies to the data made available in this article, unless otherwise stated. 


\section{Background}

Breast cancer remains the most common cancer and the second most common cause of cancer-related deaths in women [1]. The role of Neuropilin-1 (NRP-1), a multifunctional transmembrane protein that interacts with a multitude of signaling receptors, in breast cancer pathogenesis has been extensively investigated. Previously, we showed that NRP-1 is overexpressed in malignant subtypes of epithelial ovarian cancer and was positively correlated with epithelial to mesenchymal transition (EMT) markers [2]. In addition, we detected high NRP-1 expression in breast cancer MDA-MB-231 parental and metastatic variant cells [3]. Most recently, we reported upregulated plasma and tumor tissue expression of NRP-1 in breast cancer cases with advanced nodal and metastatic disease, and particularly in triple negative breast cancer compared to other molecular subtypes [4]. Overexpression of NRP-1 has also been observed in several other cancer types and is associated with tumor progression and poor patient prognosis [5]. A monoclonal antibody against NRP-1 has been tested in phase I clinical trials and shown to enhance bevacizumab-mediated vascular endothelial growth factor (VEGF) pathway blockade $[6,7]$. The crosstalk between integrin $\alpha v \beta 3$ and NRP-1 in endothelial cells limits the latter in contributing to VEGF-induced angiogenesis [8]. It has been shown that the suppression of Integrin $\beta 3$ (ITBG3) in endothelial cells activates cell migration pathway through NRP-1 mobilization away from mature focal adhesions following VEGF-stimulation [9]. In addition, integrin $\alpha v \beta 3$ was shown to control the metastatic ability of breast cancer cells to the brain in a mouse model [10]. Integrin $\alpha v \beta 3$ binds to many extra cellular matrix proteins and enhances proliferation and migration through the phosphorylation of the downstream signaling of the focal adhesion kinase pathway (FAK) [11]. Previously we showed the exclusive expression of ITGB3 in brain metastasized MDA-MB-231 cells [3]. However, the effect of NRP-1 overexpression on the ITGB3 signaling pathway and its role in chemoresistance in breast cancer has not yet been investigated. Furthermore, the role of NRP-1 in oncogenesis has been extensively investigated, in an era of advancement in omics technology there is a lack of studies dissecting the global changes elicited by NRP-1 modulation. This is of importance to identify novel pathways associated with NRP-1 function with the purpose of dual targeting in breast cancer patients to increase treatment efficiency. An additional hindrance in breast cancer treatment is the high mortality associated with chemoresistance [12]. Thus, dissecting mechanisms underlying the ability of tumor cells to develop resistance to cytotoxic drugs is of high priority in the race towards targeted and personalized therapeutics and the development of biomarkers to predict patient prognosis and drug response. Therefore, the main objectives of this study were to understand novel functional mechanism by which NRP-1 enhances breast cancer progression and to investigate the relationship of NRP-1 with acquired chemoresistance.

\section{Methods \\ Cell culture}

Human breast cancer cell lines BT-474 (300131), MCF7 (300273) and MDA-MB-231 (300275) were purchased from Cell Lines Service CLS (Germany), which authenticates cell lines using the STR DNA analysis method. BT474 cells were grown in RPMI-160 (Gibco, USA) supplemented with $10 \% \mathrm{FBS}, 50 \mu \mathrm{g} / \mathrm{ml}$ gentamicin and sodium pyruvate (Gibco, USA). All cells were maintained at $37^{\circ}$ $\mathrm{C}$ in $5 \% \mathrm{CO}_{2}$ incubators.

\section{Stable transfection of NRP-1}

The NRP-1 cDNA (GenBank accession number BX510902. 1) cloned in pDONR221 plasmid (Cat. HsCD00295948) was purchased from DNASU Plasmid Repository (USA). The cDNA fragment (2750 bp coding for the amino acids from 1 to 917 of the protein) was amplified using the following primers: NRP-1 F: 5' - GGAATTCTATGGAGAGGGGGC TGC-3' and NRP-1R: 5' - CGGGATCCTGTGTATTCAGT TTGTCTTT-3', purified using the GeneJET Gel Extraction Kit (Thermo Fisher Scientific, Lithuania), digested with EcoR-1 and BamH-1 and subcloned in frame in the pPTuner IRES2 expression plasmid (Takara Bio, USA). The cloned vector was electroporated using the Gene Pulser electroporation system (Bio-Rad, USA) into DH1OB competent E. coli cells and the positive clones were selected on LB Kanamycin plates $(100 \mathrm{mg} / \mathrm{ml})$ and confirmed by restriction enzyme analysis and DNA sequencing (Macrogen Inc., Korea). The resulting vector was stably transfected into the BT-474 cell line using Lipofectamine-2000 and positive transfected clones were isolated by the colony disk isolation method and selected using $600 \mu \mathrm{g} / \mathrm{ml}$ of Geneticin G418 antibiotic (Gibco, USA). The transfected cells were designated as BT474 NRP-1. The empty plasmid was also transfected into BT-474 cells and used as a negative vector control.

\section{Generation of chemo-resistant lines}

Chemoresistant BT-474 and BT-474 NRP-1 variant cell lines were generated in a similar protocol to that described previously [13]. Briefly, the cells were treated with four cycles of a combination of $0.5 \mathrm{uM}$ of Doxorubicin (Brand name Adriamycin, Pharmacia, Italy) + $300 \mathrm{nM}$ Cyclophosphamide (Brand name Cytoxan, Baxter, Germany) (cells will be referred to as 4xAC) followed by four cycles of $20 \mathrm{nM}$ Paclitaxel (Brand name Taxol, EBEWE Pharma, Austria) (cells will be referred to as $4 \mathrm{xAC}+4 \mathrm{xPAC})$. Each cycle was for a duration of $72 \mathrm{~h}$ followed by a recovery period until confluency 
was achieved prior to commencement of the next cycle. Protein lysate and RNA was extracted from the $4 \times A C$ and $4 x A C+4 x P A C$ resistant cell lines and stored at $-80{ }^{\circ} \mathrm{C}$.

\section{Western blotting}

Cells were lysed in $1 \times$ lysis buffer (Cell Signaling Technology, USA) supplemented with phenylmethylsulfonyl fluoride (PMSF) protease inhibitor (Sigma, Germany). Western blotting was performed according to a standard protocol as described in [3]. The primary antibodies used are listed in Additional file 1: Table S1. HRP-linked secondary rabbit/mouse antibody was utilized to detect the chemiluminescence signal using Clarity ECL (BioRad) and visualized using the ChemiDoc Touch Imaging System (Bio-Rad). Images were acquired and processed with the Image Lab software Version 5.2.1 (Bio-Rad).

\section{Quantitative real-time PCR}

RNA extraction and qRT-PCR were performed according to standard protocols as described earlier [4]. Primers were designed using the Primer Express software (Applied Biosystems, USA) and are listed in Additional file 1: Table S2.

\section{Proliferation assay}

The AlamarBlue ${ }^{\circledR}$ (GeneCopoeia, USA) proliferation assay was carried out according to the manufacturer's instructions using 80,000 cells/well.

\section{Invasion assay}

The invasive capacity of the cells was determined using the CultreCoat 96 Well Medium BME cell invasion assay (Trevigen, USA) according to the manufacturer's instructions using 25,000 cells/insert. The fluorescence was measured at $485 \mathrm{~nm}$ excitation and $520 \mathrm{~nm}$ emission using an Epoch Microplate Spectrophotometer (BioTek, USA) and the Gen5 software version 2.07.

\section{Clonogenic assay}

In this assay, $10^{4}$ cells/well were seeded in six-well plates and maintained in complete growth media for 14 days after which the cells were washed and stained with crystal violet (5\% Bromophenol Blue $+25 \%$ methanol) for 20 mins. The excess stain was washed off with distilled water and the stained colonies were counted manually.

\section{Spheroid formation}

Here, $10^{4}$ cells/well were seeded in 96 -well plates coated with $5 \%$ agarose to reduce surface binding, and maintained for seven days in complete growth media. Microscopic images were taken daily using the Axio Vert.A1 microscope, Axiocam ERc 5 s camera (Zeiss, Germany) and AxioVision software version 4.9.

\section{Wound healing assay/migration assay}

One million cells were seeded in $25 \mathrm{~cm}^{2}$ flasks (Thermo Fisher Scientific, USA) and cultured until 90\% confluency. A wound was generated in the monolayer with a sterile glass tip. The ability of the cells to migrate towards each other and close the gap generated was assessed by microscopic imaging.

\section{Immunofluorescence microscopy}

Here, $10^{6}$ cells were seeded on a sterile positively charged slide, fixed with 4\% Paraformaldehyde, permeabilized using $0.05 \%$ Triton $\mathrm{X}-100$, followed by blocking with $5 \%$ goat serum and overnight incubation with a mixture of primary anti-rabbit NRP-1 antibody (1:100) (Abcam, UK) and antimouse TNC antibody (1:200) (Santa Cruz, USA) diluted in PBS. Anti-rabbit IgG Fab2 Alexa Fluor 555 and anti-mouse IgG Fab2 Alexa Fluor 488 secondary antibody (Cell Signaling Technology) were used at a 1:400 dilution in PBS. Cells were counterstained with DAPI (1:250). Images were captured using a Nikon H600L fluorescent microscope (Japan) and NIS Elements software version 4.40.

\section{RNA sequencing}

Next generation sequencing using the Illumina HiSeq 2500 sequencing system was performed at CD Genomics (USA) for two replicates each of the control BT-474 and BT474-NRP1 cells. A total of 22,655,647 clean reads from 22,914,684 raw sequencing reads were generated upon sequencing. The count per million (CPM) method was utilized for filtering low counts/noise by NOISeq. The clean reads were mapped to the reference genome using the HISAT [14]/ Bowtie2 tool [15]. The fragments per kilobase of transcript per million mapped reads (FPKM) method was utilized to calculate the expression levels. A false detection rate (FDR) $\leq 0.001$ and the absolute value of $\log _{2}$ ratio $\geq 2$ were used as the default threshold to identify significant DEGs. DEGs were classified based on their Gene Ontology (GO) functional terms and KEGG pathway enrichment analysis using the Blast2GO software. RNA sequencing results were validated using quantitative real-time PCR.

\section{siRNA- mediated transient knockdown}

In this case, $2 \times 10^{5}$ BT-474 NRP-1 cells/well were seeded in a six-well plate in complete growth medium until $70 \%$ confluency. Cells were treated with $80 \mathrm{pmol}$ of a pool of three human TNC-targeted siRNA (Santa Cruz) or control siRNA in transfection reagent and serum-free siRNA transfection medium (Santa Cruz) according to the manufacturer's instructions.

\section{Statistical analysis}

An independent samples t-test was utilized to identify statistical differences between the BT-474 and BT-474/ 
NRP-1 cell lines. Analysis of variance (ANOVA) with the Tukey post hoc test was utilized to determine statistical differences between the resistant cell lines. Statistical analysis was based on three independent replicates. A $p$ value $<0.05$ was regarded as the threshold for statistical significance.

\section{Results}

Recombinant NRP-1 overexpression increased the tumorigenic ability of BT-474

In order to understand the functional role of NRP-1 in breast cancer progression, NRP-1 was stably overexpressed in the BT-474 cell line, which has very low baseline levels of NRP-1 compared to other breast cancer cell lines such as MDA-MB-231 and MCF-7 (Fig. 1a). NRP-1 overexpression in the transfected BT-474 NRP-1 cells was confirmed at protein level by western blotting and immunofluorescence microscopy (Fig. 1a). BT-474 NRP-1 cells displayed significantly increased migration compared to control cells three days post generation of the wound (Fig. 1b). Moreover, NRP-1 overexpression decreased the ability of the cells to form spheroids. Control BT-474 cells formed compact dense spheroids, but BT-474 NRP-1 cells either did not form spheroids or formed less dense clumps that did not adhere to form distinct spheroids (Fig. 1c). NRP-1 overexpression decreased the levels of proteins related to adhesion and migration as shown in a decrease in the cleaved active form of E-cadherin (lower band) and $\beta$-catenin (Fig. 1d), and a significant increase in gene expression of vimentin (Fig. 1e) similar to NRP-1 gene expression (Fig. 1f). NRP-1 overexpression increased the clonogenic ability of the cells as observed from the increased number of colonies in the BT-474 NRP-1 cells compared to control BT-474 (Additional file 2: Figure S1A). In addition, NRP-1 overexpression significantly increased the proliferation of the BT-474 NRP-1 cells (Additional file 2: Figure S1B). However, there was a non-significant increasing trend in the invasion ability of the BT-474 NRP-1 variant cells compared to the control BT-474 cells (Additional file 2: Figure S1C).

\section{RNA-Seq identified novel genes associated with NRP-1 overexpression}

Since NRP-1 overexpression triggered several dynamic phenotypic changes, we further sought to determine the resulting global transcriptomic variations in the BT-474 NRP-1 variant cells. 23 upregulated and 61 downregulated genes were identified in the NRP-1 overexpressing cells in comparison to wild-type BT-474 cells (Additional file 1: Table S3 and S4). Pathway analysis indicated an enrichment of genes related to viral carcinogenesis, p53 signalling pathway and the cell cycle in the BT-474 NRP-1 cells (Fig. 2a) and Binding was the most enriched gene ontology GO term related to molecular function (Fig. 2b).
Kyoto encyclopedia of genes and genomes (KEGG) classification also indicated an enrichment of genes related to signal transduction and cancers (Fig. 3a). Among the DEGs, 11 upregulated and 11 downregulated genes were shortlisted based on their known roles in cancer and/or EMT for confirmation with real-time qPCR (Additional file 1: Table S5). Consistent with observations from RNA-Seq, Tenascin C (TNC) was significantly upregulated in the BT-474 NRP-1 cells in 4 independent replicas (Fig. 3b). In addition, Angiotensin Converting Enzyme (ACE) (Fig. 3c), Apolipoprotein D (APOD) (Fig. 3d), Activating Transcription Factor 3 (ATF3) (Fig. 3e), DNA Damage induced transcript 3 (DDIT3) (Fig. 3f) and P2X purigenic receptor 6 (P2RX6) (Fig. $3 g$ ) genes were significantly downregulated in the BT-474 NRP-1 cells. The vector control cells indicated similar expression of these genes to the wild-type BT-474 cells (Fig. 3b-f).

\section{Tenascin $C$ contributes to the increased migratory} capacity of BT-474 NRP-1 cells

A candidate DEG, TNC, confirmed to be significantly upregulated by RNA-Seq and qPCR, was selected based on its known oncogenic function. The upregulation of TNC gene expression was confirmed at the protein level where BT-474 NRP-1 cells expressed a high cytoplasmic granular expression of TNC (Fig. 4a). Moreover, TNC protein expression colocalized with NRP-1 in the cytoplasm but not on the cell membrane (Fig. 4a). Knockdown of TNC expression using a pool of siRNA resulted in a 50\% downregulation in gene expression (Fig. 4b). TNC downregulation significantly reduced the migratory capacity of the BT-474 NRP-1 cells (Fig. 4c), which was supported by a concomitant and significant decrease in NRP-1 and vimentin expression (Fig. 4d).

\section{BT-474 NRP-1 cells activate TNC-associated ITGB3/FAK/ Akt/NF-kB and TNFR2 signaling}

Since TNC is known to signal via integrins on the cell surface, the expression of the integrin family was quantified. NRP-1 overexpression was found to significantly upregulate integrin $\beta 3$ (ITGB3) (Fig. 5a); however, it downregulated integrin $\beta 1$ (ITGB1) (Fig. 5a) and did not alter the expression of integrin $\beta 4$ and $\beta 5$ (data not shown). The expression of integrins $\alpha 5$, alpha- $V$ and alpha4 could be detected neither in the control nor in NRP-1 overexpressing BT-474 cells. NRP-1 overexpression increased the phosphorylation (Tyr397) of focal adhesion kinase (FAK), a known integrin effector molecule (Fig. 5a). Although a decrease in the phosphatidyl inositol3 kinase (PI3K) $110 \alpha$ catalytic subunit was observed, Akt, the downstream target of FAK, was activated in BT-474 NRP-1 cells with increased phosphorylation at site Ser473 but not site Ser308 (Fig. 5a). Akt-473 phosphorylation was further associated with a concomitant increase in glycogen 


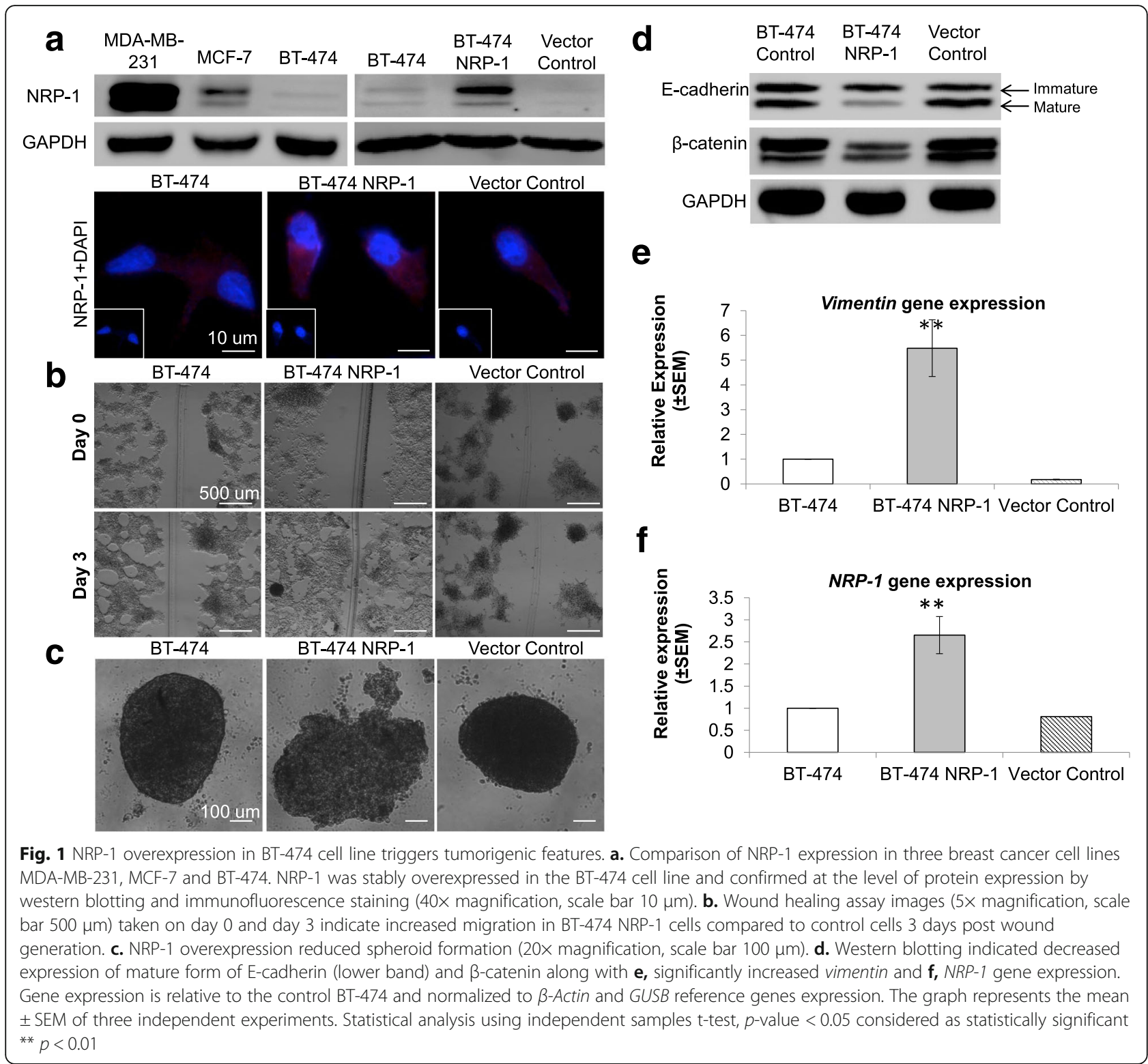

synthase kinase 3-beta (GSK3 $\beta$ ) phosphorylation at Ser9 (Fig. 5a) and activation of the downstream nuclear factor kappa B (NF-kB) pathway as observed from the upregulation of phosphorylated NF-kB p65 (Fig. 5a). siRNAmediated TNC knockdown in BT-474 NRP-1 cells reversed FAK and Akt activation by downregulating the phosphorylation of FAK at Tyr397 and Akt at Ser473 but did not affect the expression of NRP-1 (protein) or ITGB3 as shown in the representative western blots (Fig. 5b). TNC protein band was not detected on western blot due to the lack of proper antibody for this application.

As the Akt-473 pathway was observed to be upregulated in the BT-474 NRP-1 cells, the expression of additional upstream regulators of Akt signaling were analyzed. We found that BT-474 NRP-1 cells also displayed a significant upregulation of tumor necrosis factor receptor 2 (TNFR2) and downregulation of TNFR1 expression (Fig. 5c).

\section{BT-474 NRP-1 cells have increased sensitivity to} Adriamycin/cyclophosphamide exposure

To determine the role of NRP-1 in cellular response to cytotoxics, BT-474 control and BT-474 NRP-1 variant cells were treated with a combination of Adriamycin and Cyclophosphamide $(\mathrm{AC})$ for $72 \mathrm{~h}$, and their capacity to invade was assessed. Despite the more tumorigenic behavior of the BT-474 NRP-1 cells, they indicated increased sensitivity to 

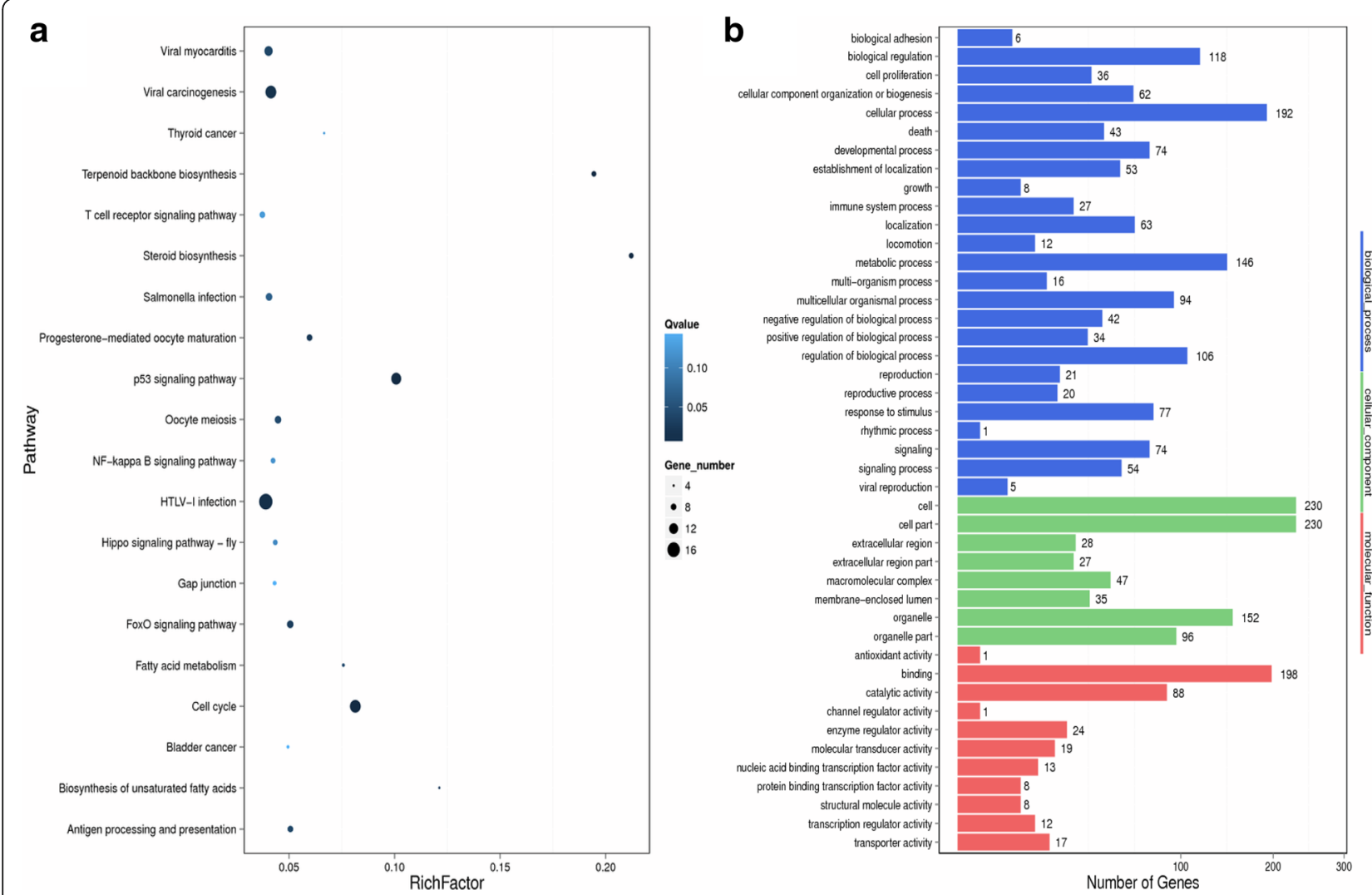

Fig. 2 Enrichment of cancer-related pathways from transcriptome-wide analysis. a. Pathway enrichment and b. Gene Ontology analysis of differentially expressed genes (DEGs) between the BT-474 and BT-474 NRP-1 cells from RNA sequencing based on a Log 2 ratio cutoff $\geq 2$ and concurrence in 2 replicates

the AC treatment as observed from the significantly reduced invasive capacity whereas the control BT-474 cells indicated a trend to increased invasion (Fig. 6a). To further understand the effect of baseline NRP-1 overexpression in increasing chemosensitivity, cells chemoresistant to AC and $\mathrm{AC}+\mathrm{PAC}$ were generated as described in the methods section, and their properties analyzed. In terms of the resistant variants of the wild-type BT-474 cells, the ability of the BT474 4xAC cells to proliferate was significantly increased compared to untreated control BT-474 cells (Fig. 6b), however the addition of Paclitaxel in the $4 x A C+4 x P A C$ resistant cells reversed the action of $4 x A C$ by decreasing the proliferative capacity of the cells to a level similar to untreated control cells (Fig. 6b). On the other hand, in the BT-474 NRP-1 cells, the 4xAC and 4xAC + 4xPAC resistant variants did not indicate alterations in proliferation compared to untreated cells (Fig. 6b). In terms of colony formation/clonogenic ability in the wild-type BT-474 resistant cells, the BT-474 4xAC and 4xAC + 4xPAC cells formed significantly more colonies compared to untreated control cells (Fig. 6c). On the other hand, in the NRP-1 overexpressing cells, BT-474 NRP-1 4xAC cells showed a significantly reduced ability to form colonies, which was increased in BT474 NRP-1 4xAC + 4xPAC resistant cells to a level similar to untreated cells (Fig. 6c).

The ability of the resistant cells to migrate and form spheroids was also assessed. In wild-type BT-474 resistant cells, the wound-healing assay indicated increased migration of the BT-474 4xAC and 4xAC + 4xPAC cells compared to the untreated control cells (Fig. 6d). However, in the BT-474 NRP-1 resistant cells, both 4xAC and 4xAC+ 4xPAC cells displayed decreased migration, with the BT474 NRP-1 4xAC + 4xPAC cells displaying minimal migration compared to the untreated cells (Fig. 6d). In the spheroid formation assay, wild-type BT-474 cells had the ability to form distinct, dense spheroids within $24 \mathrm{~h}$ of cell seeding, whereas $4 x A C$ resistant cells formed multiple smaller spheroids that remained separate even $72 \mathrm{~h}$ post seeding (Fig. 7a). Treatment with 4xAC + 4xPAC reverted the spheroid phenotype to one similar to untreated BT474 cells (Fig. 7a). On the other hand, the variant BT-474 NRP-1 untreated and 4xAC and 4xAC + 4xPAC resistant cells displayed multiple loose spheroids $24 \mathrm{~h}$ post cell seeding (Fig. 7a). After $72 \mathrm{~h}$, while the untreated variant 


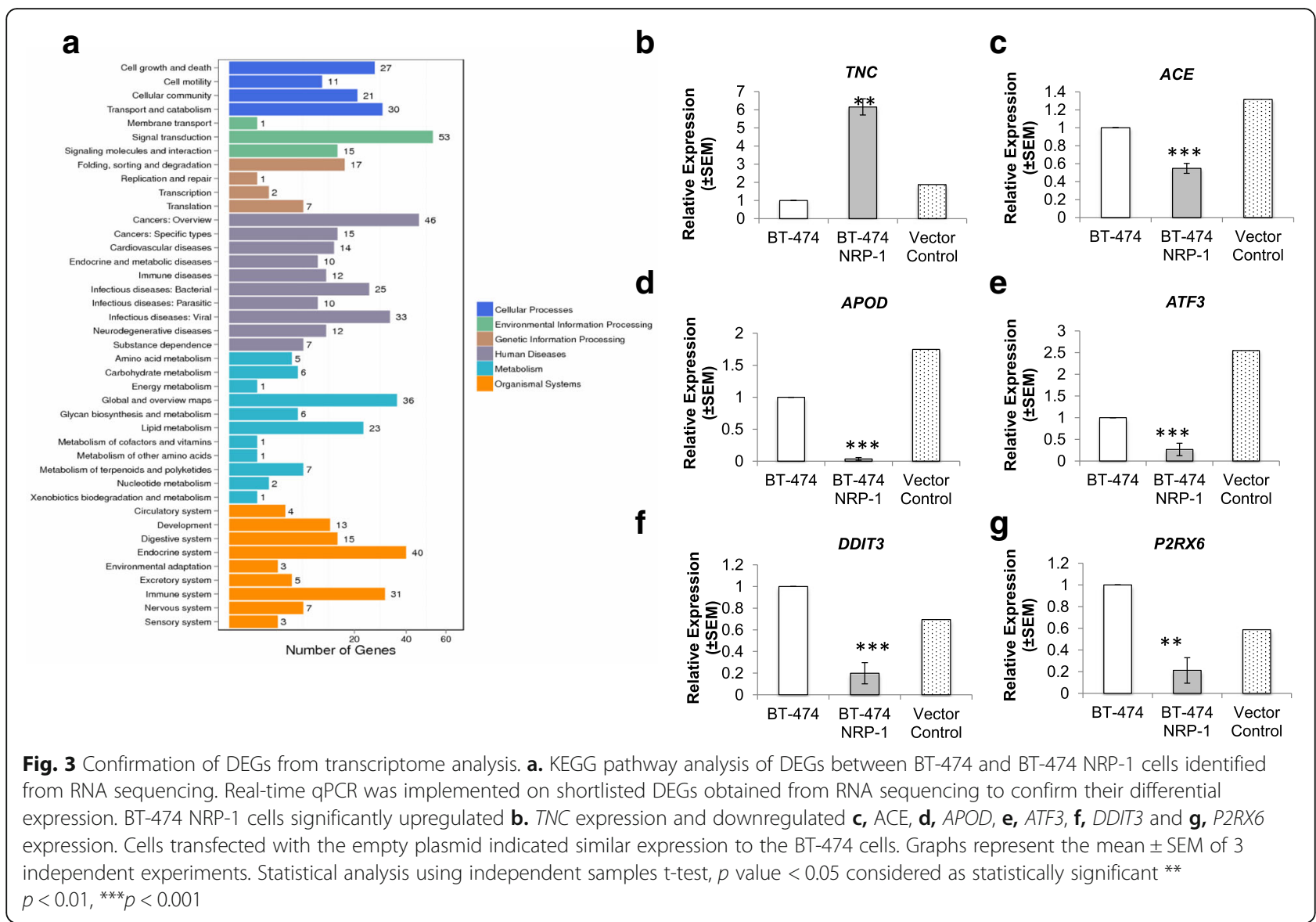

BT-474 NRP-1 spheroids had merged together to form a single large spheroid, the $4 \mathrm{xAC}$ spheroids had merged to an extent but still displayed multiple spheroids (Fig. 7a). The BT-474 NRP-1 4xAC + 4xPAC spheroids merged to form a single large, albeit loose, spheroid similar to their untreated counterpart (Fig. 7a).

\section{NRP-1 is inversely related to BCRP/ABCG2 expression}

Interestingly, the expression of breast cancer resistance protein (BCRP/ABCG2) was also found to be downregulated in BT-474 NRP-1 variant cells compared to control BT-474 and increased on short-term $\mathrm{AC}$ treatment, inversely to NRP-1 (Fig. 7b). Moreover, the expression of ABCG2 and Phospho-Akt Ser308 indicated an opposing trend to NRP-1 expression in the resistant cells also (Fig. 7c). In the control BT-474 cell line, both ABCG2 and Phospho-Akt Ser308 decreased in 4xAC resistant cells and increased to a level similar to control levels in the resistant $4 \mathrm{xAC}+4 \mathrm{xPAC}$ cells (Fig. 7c). The BT-474 NRP-1 cells, which express significantly lower levels of ABCG2 and Phospho-Akt 308 compared to control BT-474 cells, showed an upregulation in cells resistant to $4 \mathrm{xAC}$ and a decrease similar to untreated cells in the 4xAC $+4 x P A C$ resistant cells (Fig. 7c).

\section{NRP-1 and ITGB3 signaling are co-expressed and differentially regulated in BT-474 NRP-1 chemoresistant cells}

To identify the molecular changes regulating the altered chemosensitivity in the BT-474 NRP-1 cells, the expression of NRP-1 and the associated activation of the integrin signaling pathway was determined. In terms of the wildtype BT-474, resistance to $4 \mathrm{xAC}$ was associated with an upregulation of NRP-1, ITGB3 and its downstream mediators Phospho-FAK Tyr397, Phospho-Akt Ser473 and Phospho-GSK3 $\beta$, as well as the downstream transcriptional factor Phospho-NF-kB p65, compared to untreated control BT-474 cells (Fig. 7c). BT-474 resistant to 4xAC + $4 \mathrm{xPAC}$ reversed the effect of $4 \mathrm{xAC}$, by downregulating the expression of NRP-1, ITGB3, Phospho-FAK Tyr397, Phospho-Akt Ser473 and Phospho-GSK3 $\beta$ (Fig. 7c). The level of Phospho-NF-kB p65 still remained upregulated similar to the expression in 4xAC cells (Fig. 7c). 
a
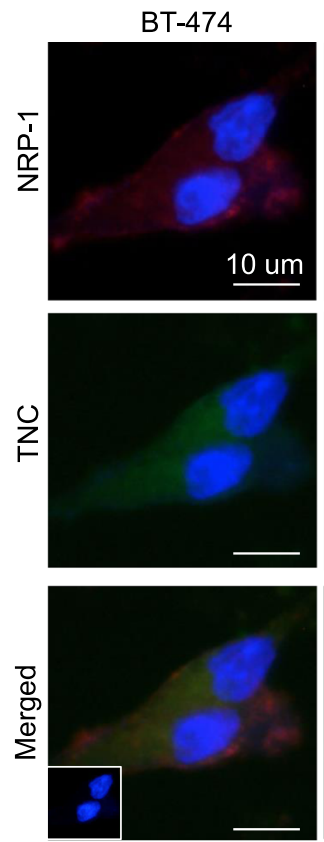

BT-474 NRP-1
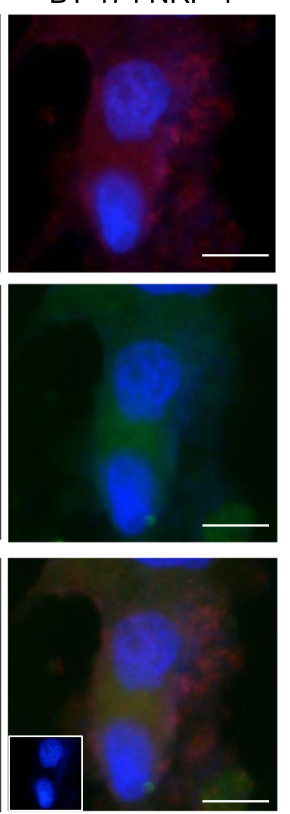

NRP-1 \& vimentin gene expression

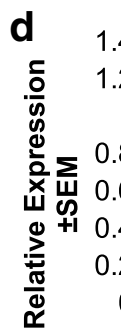

\section{Control siRNA TNC siRNA}

b

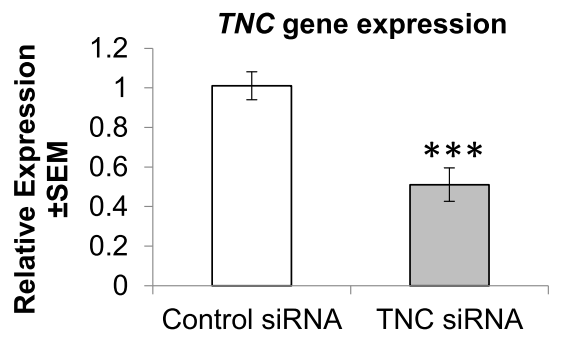

C
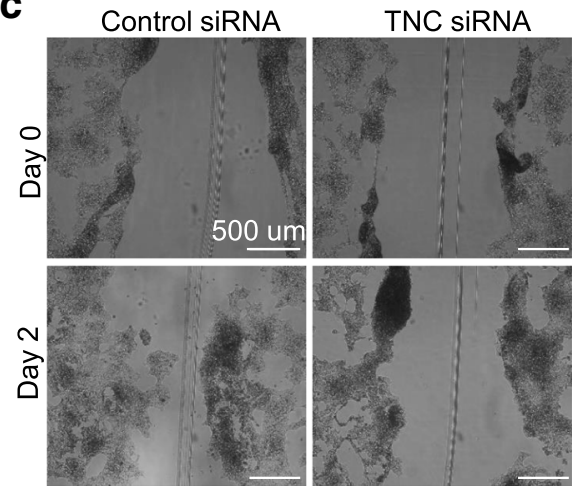

$\square N R P-1$

$\square$ Vimentin
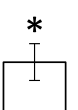

Fig. 4 Tenascin C contributes to NRP-1 associated migration. a. Dual immunofluorescence staining (40x magnification scale bar $10 \mu \mathrm{m}$ ) of NRP-1 and TNC on BT-474 and BT-474 NRP-1 cells indicates their colocalization in the cytoplasm. Treatment of BT-474 NRP-1 cells with TNC targeted siRNA molecules, $\mathbf{b}$, reduced TNC gene expression, $\mathbf{c}$, reduced migratory capacity and $\mathbf{d}$, downregulated NRP-1 and vimentin expression. (TNC protein was not detected on western blot due to the lack of specific antibody for this application.) The gene expression fold change was measured by comparing the basal levels detected in the empty plasmid transfected BT-474 or in the case of the siRNA experiment, to the control siRNA treated BT-474 and normalized to $\beta$-Actin and GUSB reference gene expression. Wound healing assay images (panel d, $5 \times$ magnification, scale bar $500 \mu m$ ) taken on day 0 and day 2 after siRNA transfection. Graphs represent the mean \pm SEM of three independent experiments. Statistical analysis using independent samples t-test, $p$-value $<0.05$ considered as statistically significant. ${ }^{*} p<0.05,{ }^{* *} p<0.01,{ }^{* *} p<0.001$

In contrast, the NRP-1 overexpressing variant BT-474 NRP-1 4xAC cells displayed a downregulation of NRP-1, ITGB3, Phospho-FAK Tyr397, Phospho-Akt Ser473, Phospho-GSK3 3 and Phospho-NF-kB p65 compared to untreated cells (Fig. 7c). While the expression of NRP-1 and ITGB3 was further downregulated in the BT-474 NRP-1 cells treated with $4 \times A C+4 \times P A C$, the addition of Paclitaxel reversed the effect of $4 \times A C$ by upregulation of Phospho-FAK Tyr397, Phospho-Akt Ser473, PhosphoGSK3 $\beta$ and Phospho-NF-kB p65 (Fig. 7c).

\section{Discussion}

The role of NRP-1 in triggering tumorigenic behavior has been indicated in several cancer types, including breast cancer [16, 17]. Moreover, depending on the ligand binding to NRP-1, it can have a dual role in different types of cells $[18,19]$. Despite the numerous roles of NRP-1, global transcriptomic effects elicited by NRP1 in cancer cells have not been previously explored and more importantly, its role in the response to chemotherapy in breast cancer has not been investigated either. In this functional study, we overexpressed NRP-1 and conducted protein analysis and total RNA sequencing to understand global changes triggered by recombinant NRP-1 overexpression. NRP-1 is coded by at least 5 splice and genetic variants [20]. In this project we overexpressed the largest NRP-1 variant which has changes in the last six amino acids (STYSEA versus DPPLSL) at the C-terminus. As the BT-474 NRP-1 cells exhibit typical cellular tumourigenic phenotypes as described in 

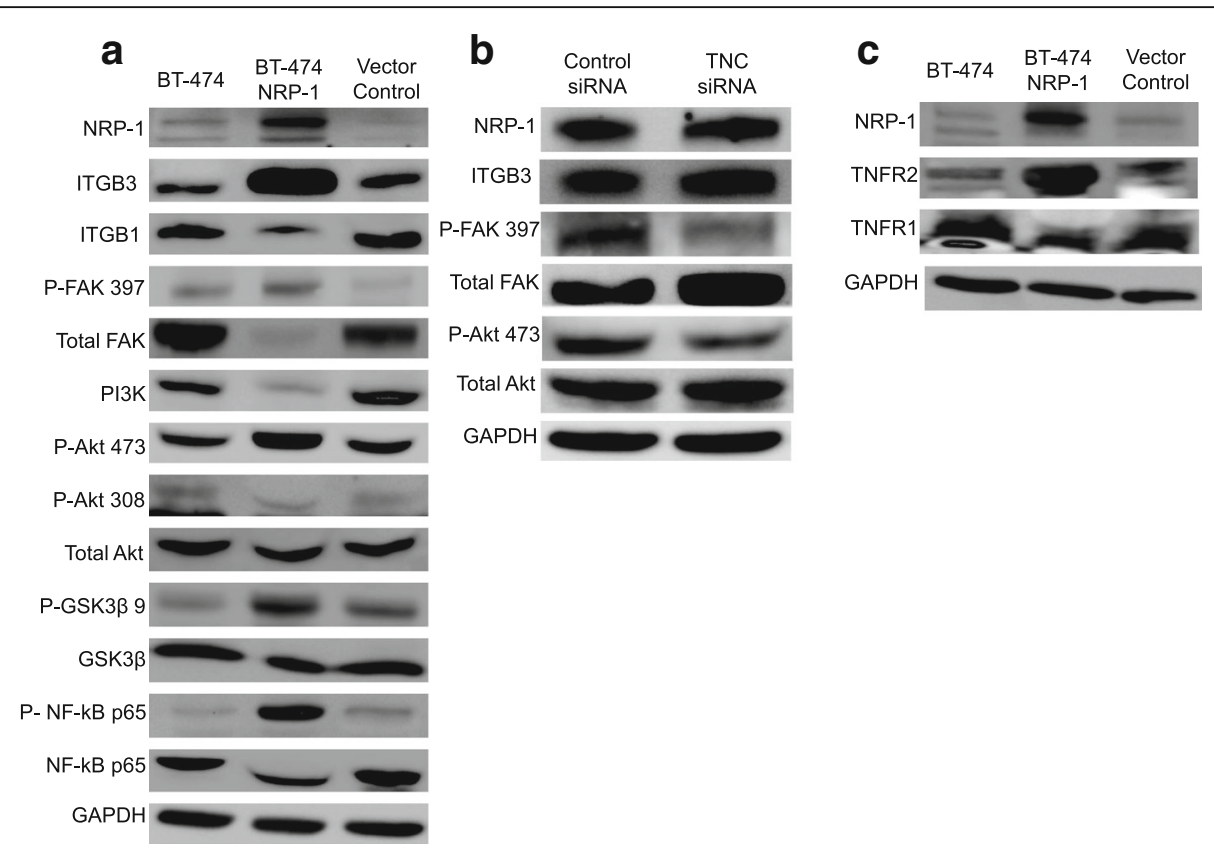

Fig. 5 NRP-1 overexpression activates integrin $\beta 3$ and TNFR2 pathways. Representative western blot images of protein lysates from untransfected BT-474, BT-474 NRP-1 and empty vector control cells blotted with indicated antibodies involved in a. Integrin signaling, and downstream signaling targets FAK, Akt, GSK3- $\beta$ and NF-kB b. siRNA-mediated TNC downregulation decreased phosphorylation of FAK and Akt-473. c. Blots show levels of tumor necrosis factor receptors (TNFRs). GAPDH protein expression is indicated as a loading control. (The prefix P beside the antibody names indicates the phosphorylated form)

this study, these conserved amino acids may not be crucial for NRP-1 function in this context. We report several genes that have not previously been associated with NRP-1 overexpression, which include oncogenes, tumor suppressors and genes involved in cancer-related pathways and protein binding function. We describe a novel association between NRP-1 and TNC expression, an extracellular matrix (ECM) glycoprotein molecule that induces EMT, migration, proliferation and immune modulations in cancer $[11,21]$. TNC triggers the cytoplasmic translocation of E-cadherin and $\beta$-catenin by Src-mediated FAK signaling in combination with $\alpha v \beta 1$ and $\alpha v \beta 6$ integrins, thus leading to enhanced migratory behavior [22]. TNC knockdown in invasive breast cancer cells was shown to reduce proliferation and invasion [23]. The common essentiality of both NRP-1 and TNC in neuronal development provides evidence for the presence of a close association between these molecules [24, 25]. Based on our observations, we report the contribution of TNC to NRP-1-triggered cell migration and activation of the FAK/Akt signaling pathway. NRP-1 and TNC upregulation was also associated with significantly increased vimentin expression and a downregulation in EMT and the tumor suppressor molecules E-cadherin (mature form) and $\beta$-catenin, that contribute to the increased clonogenic ability, migration and loss of cell-cell adhesion in the variant cells [17].
Integrins are cellular receptors that interact with the ECM and in turn activate downstream intracellular signaling pathways [26]. The dependence of NRP-1 on integrin signaling was not previously reported in breast cancer. In the BT-474 NRP-1 model, ITGB1 was downregulated and accompanied by a significant upregulation in ITGB3 expression. The loss of ITGB1 provides further evidence for the molecular mechanism of the lack of spheroid formation in the BT-474 NRP-1 cells [27]. ITGB3 expression has been linked with tumor aggression [28] and metastasis to the bone and brain in breast cancer [3] by a mechanism involving FAK and Akt signaling [29]. Our study in the BT-474 breast cancer model provides further insight into this pathway by highlighting the role of NRP-1 in triggering ITGB3/FAK/Akt-473 in a TNC-dependent pathway to trigger cell migration. Interaction studies to investigate the physical association between NRP-1, ITGB3 and TNC were limited by the lack of availability of a suitable antibody for TNC for immunoprecipitation and western blotting.

In addition, the BT-474 NRP-1 clones appear to be signaling via multiple pathways including the activation of the pro-survival TNFR2 pathway and downregulation of the apoptotic TNFR1 pathway [30], additionally explaining the increased proliferation and clonogenic ability of NRP-1 overexpressing cells. Like ITGB3, TNFR2 is also known to activate Akt phosphorylation 


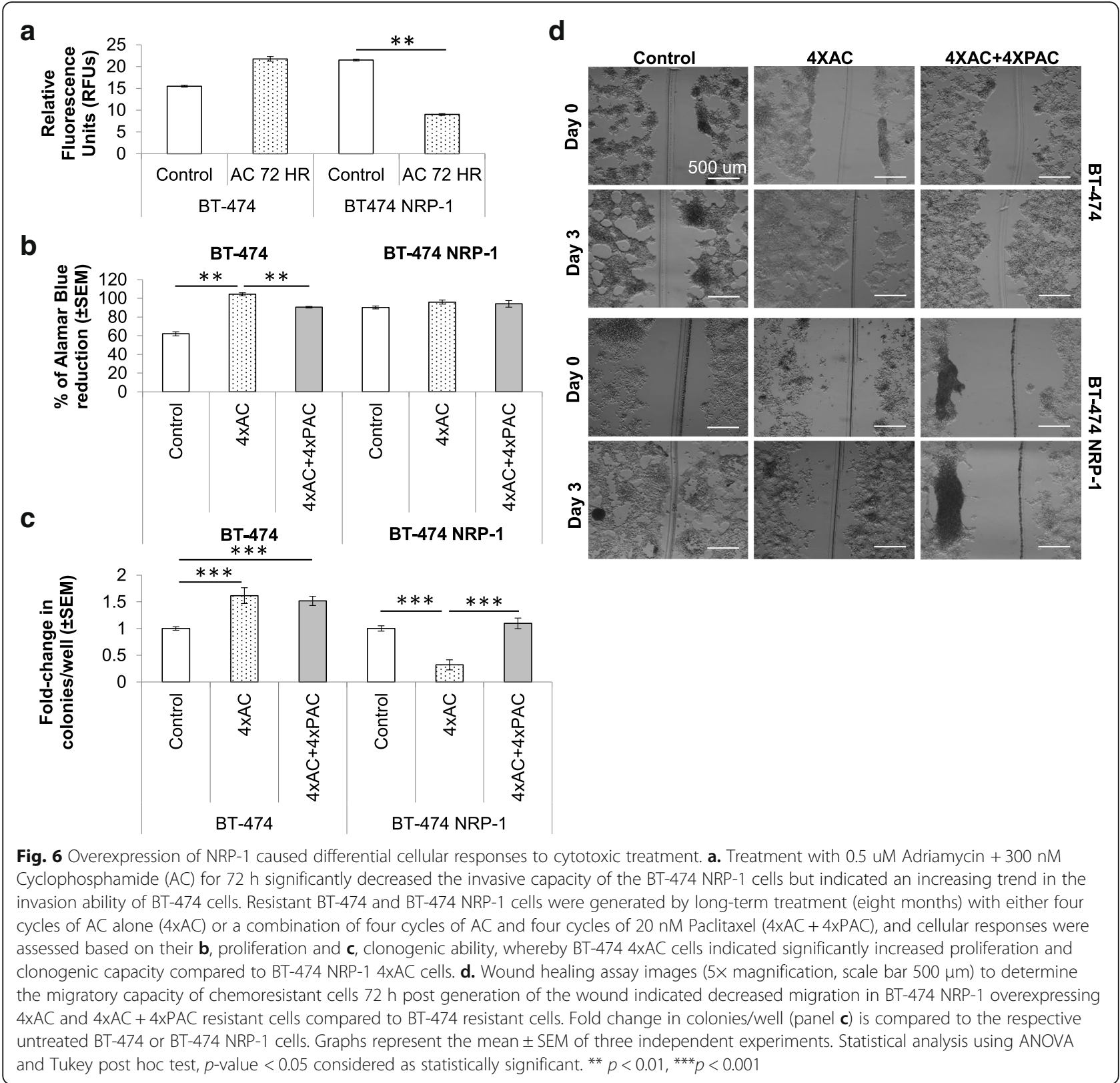

and hence, promote cellular proliferation/survival [31]. The phosphorylation of Akt at site Ser473 in our model may be directly dependent on FAK but independent of PI3K which mainly phosphorylates Akt at Ser-308 [32], both of which were downregulated in the BT-474 NRP-1 cells. The activation of Akt was also accompanied by the phosphorylation and inactivation of GSK3 $\beta$ in the NRP1 overexpressing BT-474 variant cells. Although the role of GSK3 $\beta$ is controversial, it is known to act as a tumor suppressor by regulating cell cycle proteins [33]. Thus, Akt-mediated inhibition of GSK3 $\beta$ may provide an additional mechanism by which NRP-1 exerts its prosurvival function.
A key downstream target of Akt signaling that is essential for Akt-induced oncogenic transformation is activation of NF-kB, which translocates to the nucleus and directly affects transcription of genes associated with tumorigenesis [34, 35]. We report that the increased tumorigenicity in vitro observed in NRP-1 overexpression is associated with increased activation of the p65 subunit of NF- $\mathrm{kB}$. NF- $\mathrm{kB}$ is known to drive NRP-1mediated EMT and migration in breast cancer [17]. Interestingly, NF-kB p65 was shown to promote TNC transcription in myeloid cells in an Akt-dependent pathway [36]. This evidence further strengthens the mechanistic pathway indicated in this report by which NRP-1 

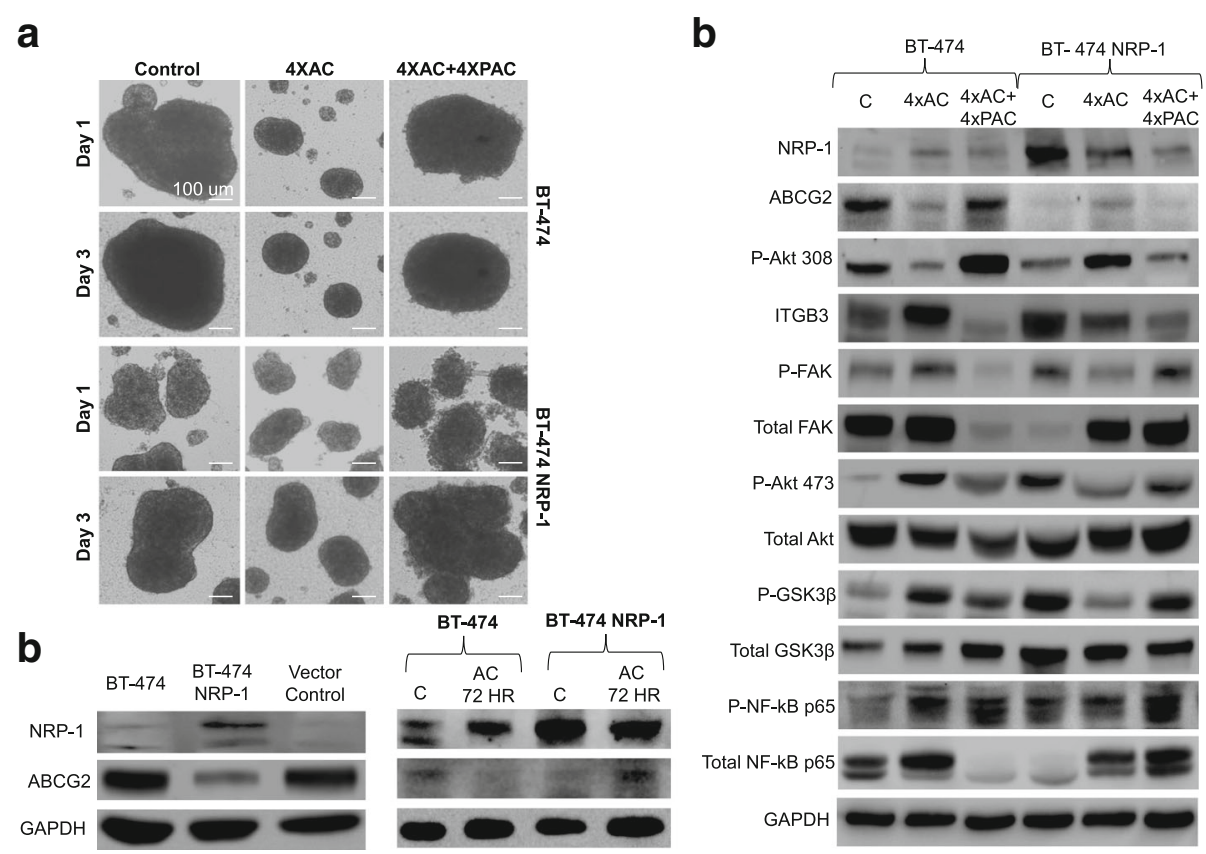

Fig. 7 Differential spheroid formation capacity and molecular profiles in NRP-1 overexpressing chemoresistant cells. a. Spheroid formation (20X magnification, scale bar $100 \mu \mathrm{m}$ ) assessed after 24 and $72 \mathrm{~h}$ in BT-474 and BT-474 NRP-1 resistant cells indicated multiple smaller spheroids in 4xAC resistant cells but similar phenotypes between the 4xAC $+4 \times P A C$ and their respective untreated controls. $\mathbf{b}$. Representative western blots to indicate NRP-1 overexpression inversely correlates with a downregulation of breast cancer resistant protein (BCRP/ABCG2) in untreated cells and on short term AC treatment for $72 \mathrm{~h}$. GAPDH protein expression is indicated as a loading control. c. Representative images from western blot analysis of BT-474 and BT-474 NRP-1 untreated, 4XAC and 4xPAC cell lysates blotted with the indicated antibodies. NRP-1 and integrin $\beta 3$ pathway molecules indicate a similar expression profile of significantly upregulated expression in BT-474 4XAC cells but a downregulation in BT-474 NRP-1 4XAC cells compared to their respective untreated controls. Images are representative of independent experiments with comparable outcomes. GAPDH protein expression is indicated as a loading control. (The prefix P beside the antibody names indicates the phosphorylated form)

overexpression induces TNC transcription by activation of Akt/NF- $\mathrm{kB}$ signaling, and this may provide a positive feedback regulation via activation of ITGB3 (Fig. 8).

NRP-1 overexpression also triggered a downregulation in APOD, ATF3 and DDIT3 expression, all of which have been associated with an inverse regulation of tumourigenesis. ATF3 is known to function as a tumour suppressor in several cancer types [37-40]. Decreased ApoD glycoprotein expression has been associated with high grade progressive invasive breast cancer [41]. DDIT3 is a transcription factor that regulates stress response and has been shown to inhibit migration and induce genes involved in growth arrest and apoptosis [42, 43]. Interestingly, DDIT3 forms heterdimers with ATF3 to regulate stress-response related genes [44]. The role of two additional genes, $P 2 X 6 R$ and $A C E$ that were confirmed to be downregulated in BT-474 NRP-1 cells is controversial. P2X receptors are purinergic ion channel receptors whose role is contradictory, cell type-specific and dependent on ATP concentration but there is a general consensus of their function in cancer cell growth inhibition, especially P2X5R and P2X7R $[45,46]$. The role of P2X6R in breast cancer has not been fully investigated, however it is likely that is has a common function as the other members of the P2X family in cancer growth inhibition. ACE, which was downregulated by NRP-1 in BT-474 cells has been reported to have pro-tumourigenic effects in various cancer types [47] although its homologue ACE2 has anti-tumour roles [48]. The role and interaction of these DEGs in association with NRP-1 need to be addressed in detail in future studies.

The role of NRP-1 in breast cancer-related chemoresistance has not been previously explored. A few reports indicated that NRP-1 downregulation or antagonism inhibited migration and enhanced chemosensitivity in non-small cell lung, kidney or prostate cancer [49] and osteosarcoma cells [50]. In pancreatic cancer cells, NRP-1 overexpression induced constitutive MAPK signaling and chemoresistance, and inhibited anoikis [51]. In this study, we report that NRP-1 inversely regulates ABCG2 expression and hence, plays a critical role in determining cellular response to chemotherapy. ABCG2 acts as an ATPbinding cassette efflux transporter for numerous anticancer agents including Adriamycin and has been implicated in eliciting multi-drug resistance [52]. High baseline expression of NRP-1 concomitant with low ABCG2 sensitizes 


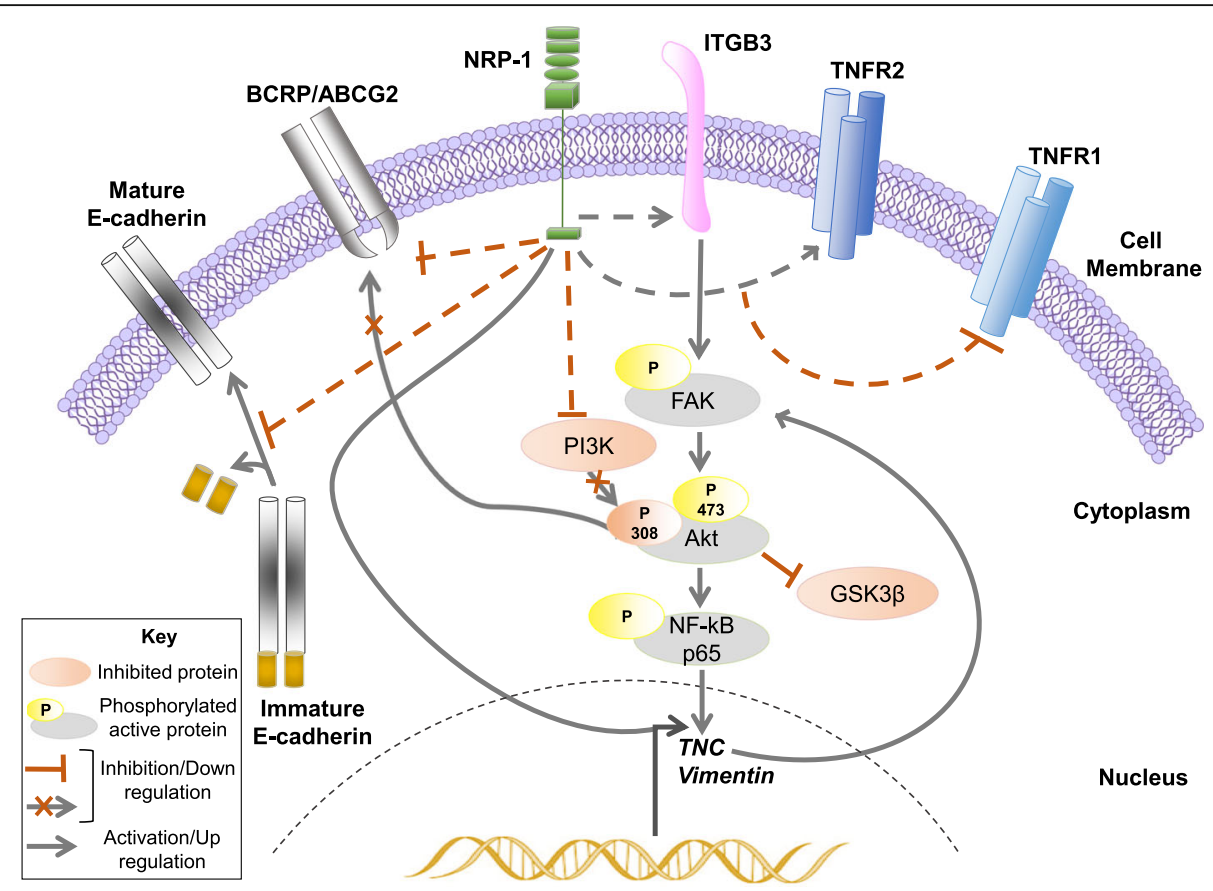

Fig. 8 NRP-1/TNC/Integrin B3/FAK/Akt/NF-kB schematic signaling pathway. Schema to illustrate the identified mechanism by which NRP-1 activates TNC-dependent integrin $\beta 3$ signaling via phosphorylation of FAK/Akt-473/NF-KB p65. In addition, NRP-1 upregulates TNFR2 expression and downregulates BCRP/ABCG2, TNFR1, and PI3K/Akt-308. Solid black lines indicate identified direct interactions in the pathway whereas dashed lines indicate indirect effects of NRP-1 overexpression via unidentified mechanisms. The key denotes the arrows and colors used in the illustration

chemo-naïve BT-474 NRP-1 cells to the effect of Adriamycin/Cyclophosphamide by decreasing NRP-1/ITGB3/FAK/ Akt signaling concurrently with decreased tumorigenic behavior. In contrast, wild-type BT-474 cells have low baseline NRP-1/high ABCG2 where 4xAC treatment upregulates the NRP-1/ITGB3 pathway and thus promotes chemoresistance. Our proposition is strengthened by the observation of high baseline NRP-1 in untreated TNBC cells such as MDA-MB231 as well as in TNBC tumors [4], which are known to be more sensitive to chemotherapy compared to other molecular subtypes [53]. Although increased NRP-1 expression in wild-type BT-474 4xAC cells is associated with lower expression of $\mathrm{ABCG} 2$, these cells display a more resistant phenotype, thus indicating that NRP- 1 is a more predictive marker of chemoresistant breast cancer than ABCG2. The direct correlation of Phospho-Akt 308 with ABCG2 but inverse correlation with NRP-1 and ITGB3 provides a mechanistic explanation of ABCG2 regulation since Phospho-Akt 308 is known to regulate the cellular localization of ABCG2, whereby inhibition of the PI3K/Akt pathway is associated with ABCG2 degradation [54].

The cellular response on addition of Paclitaxel in $4 \mathrm{xAC}+4 \mathrm{xPAC}$ resistant cells, however, showed variability. Treatment with Paclitaxel reversed the increased proliferation triggered by $4 \mathrm{xAC}$ in $\mathrm{BT}-474$ wild-type cells but did not affect the proliferation of BT-474 NRP-1 resistant variants. Thus, in the context of proliferation it seems that BT-474 4xAC cells are more sensitive to Paclitaxel in comparison to NRP-1 overexpressing BT-474 NRP-1 4xAC cells. This observation is supported by reports stating that Paclitaxel triggers the most effective response in highly proliferating cells and anthracyclineresistant cancers $[55,56]$, which is characteristic of the BT-474 4xAC cells. On the other hand, the clonogenic potential of BT-474 4xAC $+4 x$ PAC cells was similar to its $4 x A C$ counterpart, whereas in the NRP-1 overexpressing cells $4 \mathrm{xAC}+4 \mathrm{xPAC}$ treatment reversed the decreased clonogenic ability triggered by $4 \times A C$ but synergistically reduced migration compared to untreated and $4 \mathrm{xAC}$ cells. Thus, Paclitaxel seems to differentially affect various tumorigenic properties and hence, resistance to Paclitaxel, especially in combination with AC - a commonly used treatment regimen in breast cancer - needs to be further investigated.

\section{Conclusions}

In summary, we indicate for the first time the global transcriptomic changes triggered by NRP-1 overexpression in breast cancer. We report the involvement of NRP-1 in activating the ITGB3 pathway via FAK/Akt-473/NF- $\mathrm{kB}$ p65 that is dependent on TNC expression, in addition to the upregulation of pro-survival TNFR2 and downregulation 
of TNFR1, PI3K/Akt-308, (Fig. 8). Moreover, we highlight the functional role NRP-1 plays in breast cancer resistance by attenuating ABCG2. These observations support the development of targets for the NRP-1/TNC/Integrin $\beta 3$ axis and the validation of NRP- 1 as a predictive biomarker for chemoresistance in breast cancer patients.

\section{Additional files}

Additional file 1: Table S1. List of primary antibodies used. Table S2. List of RT-qPCR primer sequences. Table S3. List of significant upregulated DEGs. Table S4. List of significant downregulated DEGs. Table S5. List of shortlisted DEGs for confirmation by RT-qPCR. (DOCX 27 kb)

Additional file 2: Figure S1. Cellular response to NRP-1 overexpression. NRP-1 overexpression significantly increased $\mathbf{A}$, clonogenicity, $\mathbf{B}$, proliferation but $\mathbf{C}$, did not significantly alter invasion through a basement membrane although there was a trend to increase. Images are representative of 3 independent experiments, all with comparable outcome. Graphs represent the mean \pm SEM of 3 or more independent experiments. Statistical analysis using independent samples t-test, $p$ value $<0.05$ considered as statistically significant ${ }^{* * *} p<0.001$. (PPTX $35 \mathrm{~kb}$ )

\section{Abbreviations}

AC: Adriamycin/Cyclophosphamide; BCRP: Breast Cancer resistant Protein CPM: Counts Per Million; DEG: Differentially Expressed Gene;

ECM: Extracellular Matrix; EGFR: Epidermal Growth Factor Receptor; EMT: Epithelial-to-Mesenchymal Transition; FAK: Focal Adhesion Kinase; FDR: False Detection rate; GO: Gene Ontology; GSK3 $\beta$ : Glycogen Synthase Kinase 3 beta; ITGB3: Integrin beta 3; MAPK: Mitogen-activated Protein Kinase; NF-kB: Nuclear Factor kappa B; NRP-1: Neuropilin-1; PAC: Paclitaxel; PI3K: Phosphatidyl Inositol-3 Kinase; TNC: Tenascin C; TNFR1/2: Tumor Necrosis Factor 1/2

\section{Acknowledgements}

We thank Prof. Mansour Al-Moundhari for providing the chemotherapy drugs.

\section{Funding}

The study was funded by The Research Council of Oman grant ORG/HSS/14/ 006 (TRC\#137) given to SAA. The funding body did not contribute in any of the following: design of the study, data collection, data analysis, interpretation of data, or in writing the manuscript.

\section{Availability of data and materials}

The RNA sequencing data discussed in this publication have been deposited in NCBI's Gene Expression Omnibus and are accessible through GEO Series accession number GSE106638 (https://www.ncbi.nlm.nih.gov/geo/query/ acc.cgi?acc=GSE106638)

\section{Authors' contributions}

AN, SAA and MWY conceived and coordinated the study, designed, performed and analyzed the data. AN and SAA wrote the paper. AN, AY, NA, JS, NZ, MWY and SAA carried out the data collection, data analysis, and revised the paper. All authors have read and approved the final manuscript.

\section{Ethics approval and consent to participate}

Not applicable.

\section{Competing interests}

The authors declare that they have no competing interests.

\section{Publisher's Note}

Springer Nature remains neutral with regard to jurisdictional claims in published maps and institutional affiliations.

\section{Author details}

'Department of Biology, College of Science, Sultan Qaboos University, P. O. Box 36, Muscat, Oman. ${ }^{2}$ Department of Genetics, College of Medicine, Sultan Qaboos University, P. O. Box 35, Muscat, Oman. ${ }^{3}$ Department of Life Sciences, Hogeschool van Arnhem en Nijmegen, Kapittelweg 33, 6525 Nijmegen, EN, Netherlands.

Received: 19 December 2017 Accepted: 26 April 2018

Published online: 05 May 2018

\section{References}

1. Siegel RL, Miller KD, Jemal A. Cancer statistics, 2017. CA Cancer J Clin. 2017; 67(1):7-30.

2. Adham SA, Al Harrasi I, Al Haddabi I, Al Rashdi A, Al Sinawi S, Al Maniri A, Ba-Omar T, Coomber BL. Immunohistological insight into the correlation between neuropilin-1 and epithelial-mesenchymal transition markers in epithelial ovarian cancer. J Histochem Cytochem. 2014;62(9):619-31.

3. Adham SA, Al Rawahi H, Habib S, Al Moundhri MS, Viloria-Petit A, Coomber BL. Modeling of hypo/hyperglycemia and their impact on breast cancer progression related molecules. PLoS One. 2014;9(11):e113103.

4. Naik A, Al-Zeheimi N, Bakheit CS, Al Riyami M, Al Jarrah A, Al Moundhri MS, Al Habsi Z, Basheer M, Adham SA. Neuropilin-1 associated molecules in the blood distinguish poor prognosis breast Cancer: a cross-sectional study. Sci Rep. 2017:7(1):3301.

5. Ellis LM. The role of neuropilins in cancer. Mol Cancer Ther. 2006;5(5):1099-107.

6. Patnaik A, LoRusso PM, Messersmith WA, Papadopoulos KP, Gore L, Beeram M, Ramakrishnan V, Kim AH, Beyer JC, Mason Shih L, et al. A phase lb study evaluating MNRP1685A, a fully human anti-NRP1 monoclonal antibody, in combination with bevacizumab and paclitaxel in patients with advanced solid tumors. Cancer Chemother Pharmacol. 2014;73(5):951-60.

7. Weekes CD, Beeram M, Tolcher AW, Papadopoulos KP, Gore L, Hegde P, Xin Y, Yu R, Shih LM, Xiang $H$, et al. A phase I study of the human monoclonal anti-NRP1 antibody MNRP1685A in patients with advanced solid tumors. Investig New Drugs. 2014;32(4):653-60.

8. Robinson SD, Reynolds LE, Kostourou V, Reynolds AR, da Silva RG, Tavora B, Baker M, Marshall JF, Hodivala-Dilke KM. avß3 integrin limits the contribution of neuropilin-1 to vascular endothelial growth factor-induced angiogenesis. J Biol Chem. 2009;284(49):33966-81.

9. Ellison TS, Atkinson SJ, Steri V, Kirkup BM, Preedy ME, Johnson RT, Ruhrberg C, Edwards DR, Schneider JG, Weilbaecher K. Suppression of $\beta 3$-integrin in mice triggers a neuropilin-1-dependent change in focal adhesion remodelling that can be targeted to block pathological angiogenesis. Dis Model Mech. 2015:8(9):1105-19.

10. Lorger M, Krueger JS, O'Neal M, Staflin K, Felding-Habermann B. Activation of tumor cell integrin av $\beta 3$ controls angiogenesis and metastatic growth in the brain. Proc Natl Acad Sci. 2009;106(26):10666-71.

11. Yoshida T, Akatsuka T, Imanaka-Yoshida K. Tenascin-C and integrins in cancer. Cell Adhes Migr. 2015;9(1-2):96-104

12. Yu D, Hung M-C. Breast cancer chemosensitivity, vol 608. In: Springer Science \& Business Media; 2009.

13. Kopp F, Oak PS, Wagner E, Roidl A. miR-200c sensitizes breast cancer cells to doxorubicin treatment by decreasing TrkB and Bmi1 expression. PLoS One. 2012;7(11):e50469.

14. Kim D, Langmead B, Salzberg SL. HISAT: a fast spliced aligner with low memory requirements. Nat Methods. 2015;12(4):357-60.

15. Langmead B, Trapnell C, Pop M, Salzberg SL. Ultrafast and memory-efficient alignment of short DNA sequences to the human genome. Genome Biol. 2009:10(3):R25.

16. Bachelder RE, Crago A, Chung J, Wendt MA, Shaw LM, Robinson G, Mercurio AM. Vascular endothelial growth factor is an autocrine survival factor for neuropilin-expressing breast carcinoma cells. Cancer Res. 2001; 61(15):5736-40.

17. Luo M, Hou L, Li J, Shao S, Huang S, Meng D, Liu L, Feng L, Xia P, Qin T, et al. VEGF/NRP-1axis promotes progression of breast cancer via enhancement of epithelial-mesenchymal transition and activation of NF-kappaB and beta-catenin. Cancer Lett. 2016;373(1):1-11.

18. Bachelder RE, Lipscomb EA, Lin X, Wendt MA, Chadborn NH, Eickholt BJ, Mercurio AM. Competing autocrine pathways involving alternative neuropilin-1 ligands regulate chemotaxis of carcinoma cells. Cancer Res. 2003;63(17):5230-3. 
19. Gray MJ, Wey JS, Belcheva A, McCarty MF, Trevino JG, Evans DB, Ellis LM, Gallick GE. Neuropilin-1 suppresses tumorigenic properties in a human pancreatic adenocarcinoma cell line lacking neuropilin-1 coreceptors. Cancer Res. 2005;65(9):3664-70.

20. Rossignol M, Gagnon ML, Klagsbrun M. Genomic organization of human neuropilin-1 and neuropilin-2 genes: identification and distribution of splice variants and soluble isoforms. Genomics. 2000;70(2):211-22.

21. Katoh D, Nagaharu K, Shimojo N, Hanamura N, Yamashita M, Kozuka Y, Imanaka-Yoshida K, Yoshida T. Binding of alphavbeta1 and alphavbeta6 integrins to tenascin-C induces epithelial-mesenchymal transition-like change of breast cancer cells. Oncogene. 2013;2:e65.

22. Nagaharu K, Zhang X, Yoshida T, Katoh D, Hanamura N, Kozuka Y, Ogawa T, Shiraishi T, Imanaka-Yoshida K. Tenascin C induces epithelial-mesenchymal transition-like change accompanied by SRC activation and focal adhesion kinase phosphorylation in human breast cancer cells. Am J Pathol. 2011; 178(2):754-63.

23. Alharth AS, Alyami WA. Tenascin-C (TNC) promotes breast Cancer cell invasion and proliferation: functional effects of TNC knockdown in highly invasive breast Cancer cell lines. Am J Med Biol Research. 2015:3(2):55-61.

24. Telley L, Cadilhac C, Cioni JM, Saywell V, Jahannault-Talignani C, Huettl RE, Sarrailh-Faivre C, Dayer A, Huber AB, Ango F. Dual function of NRP1 in axon guidance and subcellular target recognition in cerebellum. Neuron. 2016; 91(6):1276-91.

25. Giblin SP, Midwood KS. Tenascin-C: form versus function. Cell Adhes Migr. 2015:9(1-2):48-82.

26. Harburger DS, Calderwood DA. Integrin signalling at a glance. J Cell Sci. 2009;122(Pt 2):159-63.

27. Casey RC, Burleson KM, Skubitz KM, Pambuccian SE, Oegema TR Jr, Ruff LE, Skubitz AP. Beta 1-integrins regulate the formation and adhesion of ovarian carcinoma multicellular spheroids. Am J Pathol. 2001;159(6):2071-80.

28. Furger KA, Allan AL, Wilson SM, Hota C, Vantyghem SA, Postenka CO, Al-Katib W, Chambers AF, Tuck AB. Beta(3) integrin expression increases breast carcinoma cell responsiveness to the malignancy-enhancing effects of osteopontin. Mol Cancer Res. 2003;1(11):810-9.

29. Wendt MK, Schiemann WP. Therapeutic targeting of the focal adhesion complex prevents oncogenic TGF-beta signaling and metastasis. Breast Cancer Res. 2009;11(5):R68.

30. Naude PJ, den Boer JA, Luiten PG, Eisel UL. Tumor necrosis factor receptor cross-talk. FEBS J. 2011;278(6):888-98.

31. Wang J, Al-Lamki RS. Tumor necrosis factor receptor 2: its contribution to acute cellular rejection and clear cell renal carcinoma. Biomed Res Int. 2013; 2013:821310.

32. Vadlakonda L, Dash A, Pasupuleti M, Anil Kumar K, Reddanna P. The paradox of Akt-mTOR interactions. Front Oncol. 2013;3:165

33. Georgescu MM. PTEN tumor suppressor network in PI3K-Akt pathway control. Genes Cancer. 2010;1(12):1170-7.

34. Hoesel B, Schmid JA. The complexity of NF-kappaB signaling in inflammation and cancer. Mol Cancer. 2013;12:86.

35. Bai D, Ueno L, Vogt PK. Akt-mediated regulation of NFkappaB and the essentialness of NFkappaB for the oncogenicity of PI3K and Akt. Int J Cancer. 2009;125(12):2863-70.

36. Goh FG, Piccinini AM, Krausgruber T, Udalova IA, Midwood KS. Transcriptional regulation of the endogenous danger signal tenascin-C: a novel autocrine loop in inflammation. J Immunol. 2010;184(5):2655-62.

37. Hackl C, Lang SA, Moser C, Mori A, Fichtner-Feigl S, Hellerbrand C, Dietmeier W, Schlitt HJ, Geissler EK, Stoeltzing O. Activating transcription factor-3 (ATF3) functions as a tumor suppressor in colon cancer and is up-regulated upon heat-shock protein 90 (Hsp90) inhibition. BMC Cancer. 2010;10:668.

38. Xie JJ, Xie YM, Chen B, Pan F, Guo JC, Zhao Q, Shen JH, Wu ZY, Wu JY, Xu LY, et al. ATF3 functions as a novel tumor suppressor with prognostic significance in esophageal squamous cell carcinoma. Oncotarget. 2014;5(18):8569-82.

39. Wang Z, Xu D, Ding HF, Kim J, Zhang J, Hai T, Yan C. Loss of ATF3 promotes Akt activation and prostate cancer development in a Pten knockout mouse model. Oncogene. 2015:34(38):4975-84

40. Wei S, Wang H, Lu C, Malmut S, Zhang J, Ren S, Yu G, Wang W, Tang DD, Yan $C$. The activating transcription factor 3 protein suppresses the oncogenic function of mutant p53 proteins. J Biol Chem. 2014;289(13): 8947-59.

41. Soiland $H$, Soreide $K$, Janssen EA, Korner H, Baak JP, Soreide JA. Emerging concepts of apolipoprotein D with possible implications for breast cancer. Cell Oncol. 2007;29(3):195-209.
42. Jauhiainen A, Thomsen C, Strombom L, Grundevik P, Andersson C, Danielsson A, Andersson MK, Nerman O, Rorkvist L, Stahlberg A, et al. Distinct cytoplasmic and nuclear functions of the stress induced protein DDIT3/CHOP/GADD153. PLoS One. 2012;7(4):e33208.

43. Li T, Su L, Lei Y, Liu X, Zhang Y, Liu X. DDIT3 and KAT2A proteins regulate TNFRSF10A and TNFRSF10B expression in endoplasmic reticulum stressmediated apoptosis in human lung Cancer cells. J Biol Chem. 2015;290(17): 11108-18.

44. Chen BP, Wolfgang CD, Hai T. Analysis of ATF3, a transcription factor induced by physiological stresses and modulated by gadd153/Chop10. Mol Cell Biol. 1996;16(3):1157-68.

45. Burnstock G, Di Virgilio F. Purinergic signalling and cancer. Purinergic Signal. 2013:9(4):491-540.

46. Zhou JZ, Riquelme MA, Gao X, Ellies LG, Sun LZ, Jiang JX. Differential impact of adenosine nucleotides released by osteocytes on breast cancer growth and bone metastasis. Oncogene. 2015;34(14):1831-42.

47. Wegman-Ostrosky T, Soto-Reyes E, Vidal-Millan S, Sanchez-Corona J. The renin-angiotensin system meets the hallmarks of cancer. J ReninAngiotensin-Aldosterone Syst. 2015;16(2):227-33.

48. Yu C, Tang W, Wang Y, Shen Q, Wang B, Cai C, Meng X, Zou F. Downregulation of ACE2/Ang-(1-7)/mas axis promotes breast cancer metastasis by enhancing store-operated calcium entry. Cancer Lett. 2016; 376(2):268-77

49. Jia H, Cheng L, Tickner M, Bagherzadeh A, Selwood D, Zachary I. Neuropilin1 antagonism in human carcinoma cells inhibits migration and enhances chemosensitivity. Br J Cancer. 2010;102(3):541-52.

50. Yue B, Ma JF, Yao G, Yang MD, Cheng H, Liu GY. Knockdown of neuropilin-1 suppresses invasion, angiogenesis, and increases the chemosensitivity to doxorubicin in osteosarcoma cells - an in vitro study. Eur Rev Med Pharmacol Sci. 2014;18(12):1735-41.

51. Wey JS, Gray MJ, Fan F, Belcheva A, McCarty MF, Stoeltzing O, Somcio R, Liu W, Evans DB, Klagsbrun M, et al. Overexpression of neuropilin-1 promotes constitutive MAPK signalling and chemoresistance in pancreatic cancer cells. Br J Cancer. 2005;93(2):233-41.

52. Nakanishi T, Ross DD. Breast cancer resistance protein (BCRP/ABCG2): its role in multidrug resistance and regulation of its gene expression. Chin J Cancer. 2012:31(2):73-99.

53. Isakoff SJ. Triple-negative breast cancer: role of specific chemotherapy agents. Cancer J. 2010;16(1):53-61.

54. Takada T, Suzuki H, Gotoh Y, Sugiyama Y. Regulation of the cell surface expression of human BCRP/ABCG2 by the phosphorylation state of Akt in polarized cells. Drug Metab Dispos. 2005;33(7):905-9.

55. Fjallskog ML, Frii L, Bergh J. Paclitaxel-induced cytotoxicity-the effects of cremophor EL (castor oil) on two human breast cancer cell lines with acquired multidrug resistant phenotype and induced expression of the permeability glycoprotein. Eur J Cancer. 1994;30A(5):687-90.

56. Liebmann JE, Cook JA, Lipschultz C, Teague D, Fisher J, Mitchell JB. Cytotoxic studies of paclitaxel (Taxol) in human tumour cell lines. $\mathrm{Br}$ Cancer. 1993;68(6):1104-9.

\section{Ready to submit your research? Choose BMC and benefit from:}

- fast, convenient online submission

- thorough peer review by experienced researchers in your field

- rapid publication on acceptance

- support for research data, including large and complex data types

- gold Open Access which fosters wider collaboration and increased citations

- maximum visibility for your research: over $100 \mathrm{M}$ website views per year

At BMC, research is always in progress.

Learn more biomedcentral.com/submissions 